\title{
NeOLIBERALISM AND THE IDEOLOGICAL CONSTRUCTION OF EQUITY BELIEFS
}

\author{
in press at Perspectives on Psychological Science

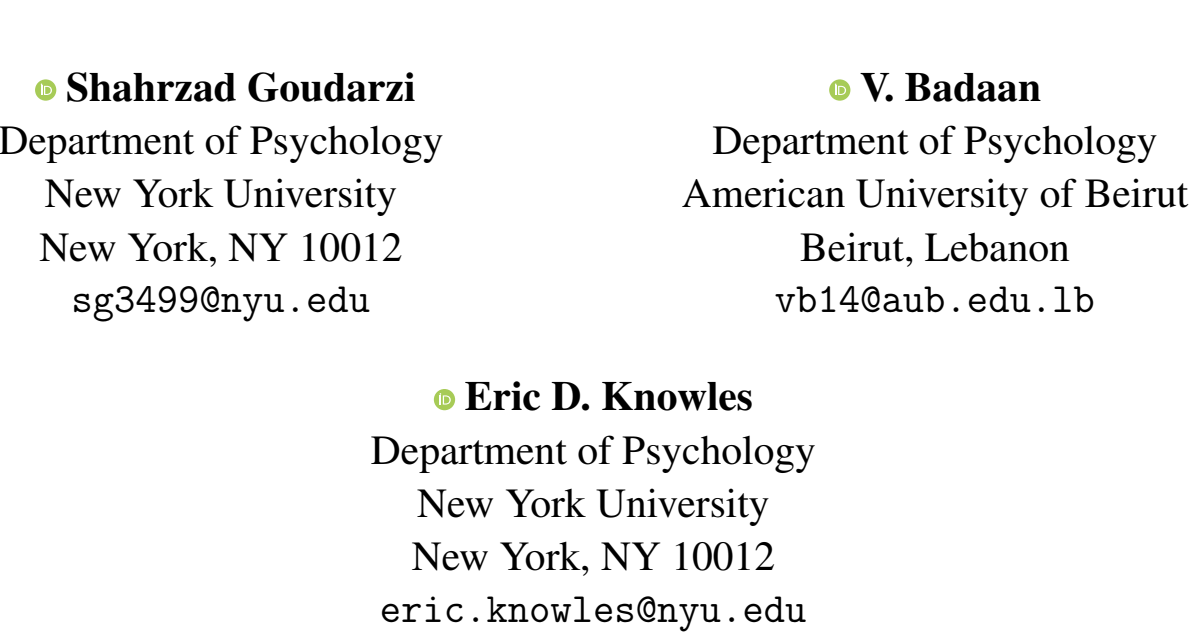

\begin{abstract}
Researchers across disciplines, including psychology, have sought to understand how people evaluate the fairness of resource distributions. Equity, defined as proportionality of rewards to merit, has dominated the conceptualization of distributive justice in psychology, with some scholars casting it as the primary basis on which distributive decisions are made. The present paper acts as a corrective to this disproportionate emphasis on equity. Drawing on findings from different subfields, we argue that people possess a range of beliefs about how valued resources should be allocated-beliefs that vary systematically across developmental stages, relationship types, and societies. By reinvigorating notions of distributive justice put forth by the field's pioneers, we further argue that prescriptive beliefs concerning resource allocation are ideological formations embedded in socioeconomic and historical contexts. Fairness beliefs at the micro-level are thus shaped by those beliefs' macro-level instantiations. In a novel investigation of this process, we consider neoliberalism, the globally-dominant socioeconomic model of the past forty years. Using data from more than 160 countries, we uncover evidence that neoliberal economic structures shape equity-based distributive beliefs at the individual level. We conclude by advocating an integrative approach to the study of distributive justice that bridges microand macro-level analyses.
\end{abstract}

Keywords Distributive Justice $\cdot$ Equity $\cdot$ Equality $\cdot$ Neoliberalism $\cdot$ Ideology 
Scholars from a range of disciplines, including philosophy, economics, sociology, and psychology, have long sought to understand how people make distributive decisions in resourceallocation contexts. Which justice principles do we employ in evaluating whether a distribution is fair? In justice reasoning based on the equity $\left.\right|^{1}$ rule, resources and rewards ("outcomes") are shared according to individuals' merits - that is, their "inputs" to the system or collective. Individual merit, in turn, can be assessed along a number of dimensions, such as effort, ability, or productivity. In the psychological sciences, the equity rule has often been given primacy as the allocation principle most often undergirding human fairness perceptions (e.g., J. S. Adams, 1965; Graham et al., 2013; Hatfield \& Walster, 1975; Homans, 1974; Starmans et al., 2017). The present article is intended as a corrective to this (often tacit) assumption. We argue that distributive beliefs are diverse and heavily contingent on the social and ideological systems in which people are embedded.

In this article, we review psychological literature suggesting that distributive beliefs vary considerably across developmental stages, persons, cultures, and economic structures. Further, we present evidence to suggest that equity beliefs are products of ideologies ${ }^{2}$ embedded in social and economic institutions. In an empirical demonstration of this process, we examine the case of neoliberalism - the dominant socioeconomic approach from the late 1970s to the present, which advocates privatization, abolition of the welfare state, and curtailment of redistributive programs. Our longitudinal analysis, spanning two decades (1995-2019) and over 160 countries, suggests that neoliberal systems contribute to the production of equity-based distributive beliefs. We conclude that distributive beliefs are better understood as socially-constructed ideologies than as universal preferences; they represent an ideological constellation of norms, beliefs, and values shaped by institutional structures. Finally, we propose avenues for future research that consider micro- and macro-level analyses of distributive beliefs and of ideology more broadly.

\footnotetext{
${ }^{1}$ Other terms — such as merit, desert, proportionality, reciprocity, responsibility, and differentiation—have also been used to refer to equity in various literatures.

${ }^{2}$ By ideology, we are referring to a collection of institutions, practices, laws, policies, beliefs, norms, and values pertaining to how society is and ought to be structured, (re)produced through the interaction of "top-down" (structural or societal) factors and "bottom-up" psychological proclivities (Jost et al., 2009).
} 


\section{Definitions}

To make clear where our views do (and do not) diverge from those of other scholars, some definitions are necessary:

1. Philosophical and social-theoretic treatments of distributive justice (e.g., those of John Rawls, 2020, and Robert Nozick , 2007), involve normative arguments and attempts to determine which principles of resource allocation are justified or "correct."

2. In the psychological study of distributive justice, prescriptive beliefs refer to those principles that laypeople regard as fair, socially appropriate, or moral. For instance, a person may believe that resources should be allocated according to recipients' relative levels of merit; alternatively, they may prefer a society in which resources are allocated such that all recipients' needs are equally met.

3. In contrast to prescriptive beliefs, descriptive distributive-justice beliefs represent appraisals of whether a particular allocation principle is being faithfully realized in practice. For example, two people who share the prescriptive belief in justice-as-equity may disagree as to whether society, as presently constituted, succeeds in dividing resources in an equitable manner.

The present work is concerned primarily with people's prescriptive beliefs concerning resource allocation (i.e., beliefs about how valued social goods should be distributed within society) and the psychological underpinnings of such beliefs. Thus, we do not address philosophical debates concerning distributive principles. Nor are we centrally concerned with people's descriptive beliefs about distributive justice — although, as elaborated later, analyses of descriptive beliefs employ notions of ideological construction that we borrow to understand the formation of people's prescriptive distributive-justice beliefs.

\section{Alternative Principles of Distributive Justice}

The concept of distributive justice has a long history in social and political thought. A constituent of social justice, distributive justice is concerned with the principles that underlie 
political, economic, and social frameworks for allocating wealth, rewards, and costs within a society. Distributive justice has been defined as "a state of affairs (either actual or ideal) in which [...] benefits and burdens in society are dispersed in accordance with some allocation principle" (Jost \& Kay, 2010, p. 1122).

In distributive systems based on the equity principle, the goal is to reach a proportionate ratio of merit ("input") to outcome ("output") for each individual. Depending on the allocation context, merit might be defined according to any number of factors-including effort, motivation, industriousness, talent, or ability. Outcome, in turn, could refer to any form of reward relevant to the context, such as wages and salary, entrance into an organization, or social recognition. For instance, a college applicant might be deemed to merit admission to a prestigious university in light of her scholastic ability, or a worker might be seen to merit a higher salary due to his track record of effort and dedication.

Distinctions between equity and other principles of distributive justice appear as early as Aristotle's (384-322 B.C.E.) Nicomachean Ethics. Two important alternatives to equity-equality and need-figure prominently in debates between advocates of Marxian, liberal-progressive, and conservative formulations of justice (Jost \& Kay, 2010). When the equality principle governs distributions, members of a collective are provided the same amount of some resource, regardless of their personal characteristics. For instance, Covid-19 vaccinations in the United States proceed on the principle that every adult resident is equally eligible to be immunized. According to the need rule, in contrast, distributions are proportioned according to individuals' preexisting resources. Illustrating this, the U.S. Internal Revenue Service grants the earned income tax credit only to low-income taxpayers, and few would be surprised if a soup kitchen refused to serve affluent clients.

Some formulations of distributive justice (e.g., Deutsch, 1975; Miller, 2001) distinguish between equal and need-based allocations. However, many philosophical and social-theoretic treatments regard equality and need as constituents of a single principle. On this principle, benefits and burdens are calibrated to needs of individuals, with the goal of equalizing people's ultimate outcomes (Cook \& Hegtvedt, 1983; Sampson, 1975). The equality/need rule is apparent in Marx's Critique of the Gotha Programme (1875/2008), in which he describes the underlying principle 
of communism as "[...] from each according to their ability, to each according to their need" such that "[...] the proceeds of labor belong undiminished with equal right to all members of society." Similarly, Hochschild's (1981) sociological analysis of fairness beliefs treats equality and need as components of the same justice principle. She notes that need-based distributions can be characterized as "subjective equality," in which the aim is not to achieve strictly equal distributions but rather to equally meet everyone's material and psychological needs (see also Cook \& Hegtvedt, 1983).

\section{Psychological Research into Distributive Justice: A Brief History}

Psychologists, naturally, are interested less in philosophical considerations than in the allocation rules people actually use in making distributive decisions and fairness appraisals. In assessing the importance of the equity principle and its alternatives to the psychological study of distributive justice beliefs, a brief chronological account of relevant scholarship is useful.

\section{Early Emphasis on Equity as the Basis of Prescriptive Justice}

In social psychology, Equity Theory (ET; J. S. Adams, 1965; Blau, 2017; Frankena, 1966; Hatfield et al., 1978; Leventhal \& Anderson, 1970) attained prominence in the 1960s and 70s. ET identifies equity-based reasoning as the foundation of most distributive judgments. Using an exchange-based framework (Homans, 1974), ET theorists view human relations as transactions in which people prefer a proportional ratio of inputs (e.g., effort, productivity, ability, time, talent) to outcomes (e.g., advantages, payment, income, wealth, social or material rewards). According to the ET approach, equity is not just a principle for making distributive decisions, but also what underlies fairness intuitions in most human interactions-even those that are non-economic in nature. For instance, close or romantic relationships with disproportionate input to outcome ratios tend to be frustrating, unsatisfying, and perceived as unfair (Boll et al., 2003; Van den Bos et al., 2006).

Despite its early predominance, ET immediately attracted critics. In particular, Morton Deutsch and Melvin Lerner - two pioneers in the study of the psychology of justice_criticized ET for limiting the conception of justice to equity. We will discuss their contributions in greater detail in later sections. 


\section{A Shift to the Study of Descriptive Justice}

Since these early analyses of prescriptive equity, psychologists in the 1980s to the present have directed much of their attention to a different issue: laypeople's descriptive beliefs concerning distributive justice (e.g., Hochschild, 1981; Jost \& Hunyady, 2003; Jost \& Thompson, 2000; Kluegel \& Smith, 2017). This literature examines the sources and consequences of people's judgments of whether current societal arrangements meet the criteria for particular distributive principles (often equity).

Research into descriptive beliefs has yielded important insights. Conducted primarily in the context of the U.S. and the "American Dream," this work elucidates how people's widespread belief in social mobility and the equity of the system (Davidai \& Gilovich, 2018; Hochschild, 1981; Kluegel \& Smith, 2017) justifies social inequality by casting it as the result of differences in merit rather than inequalities of opportunity (Madeira et al., 2019; Major \& Kaiser, 2017; McCoy \& Major, 2007; Shariff et al., 2016). Believing that one's current system is fair serves emotional functions as well- "palliating" the otherwise aversive realization that one's society is shot through with injustice (Goudarzi et al., 2020; Jost \& Hunyady, 2003, Napier et al., 2020).

Importantly, while the justice literature has until recently focused primarily on analyses of laypeople's descriptive beliefs, some researchers continued to examine the complexity of our prescriptive beliefs. (Hochschild, 1981), for instance, identifies limits on U.S. Americans' prescriptive preference for equity over equality, finding that they tend to endorse equity in socioeconomic matters but equality in the private and political spheres. Davey and colleagues (1999) regard "preference for the merit principle" (i.e., prescriptive equity) as an individual-difference dimension existing alongside the endorsement of alternative principles, such as need and equality. Rasinski (1987), too, distinguishes between equality and equity principles in his two-dimensional measure of prescriptive fairness beliefs.

Scholarship on descriptive equity casts distributive-fairness beliefs as the product of ideological processes (e.g., the influence of macro-level structures as well as the motivation to justify extant social systems) ${ }_{3}^{3}$ In this paper, we argue that such notions of ideological construction should be

\footnotetext{
${ }^{3}$ This is also true for the few exceptions mentioned above on prescriptive equity-namely, Rasinski (1987), Hochschild (1981), and Davey and colleagues (1999)
} 
applied to questions of prescriptive equity as well. Inspired by the literature on descriptive equity, as well as early prescriptive treatments of distributive justice in psychology (such as that developed by Deutsch), we argue for a broader conception of fairness that emphasizes macro-structural and individual-level factors.

\section{A Resurgence of Equity-Based Analyses of Prescriptive Justice}

In line with the assumptions of ET, some psychologists have recently begun again to identify distributive justice with (prescriptive) equity, while tending to neglect alternative justice principles. For instance, Moral Foundations Theory (MFT; Graham et al., 2013) recognizes fairness (also referred to as reciprocity by MFT theorists) as one of the five moral foundations and, like ET, conceives of fairness as proportional sharing in exchange relationships. Other fields-in particular, behavioral economics, comparative psychology, and evolutionary psychology—have further encouraged a limited view of distributive justice as equity.

\section{Behavioral Economics}

Theories in behavioral economics have often characterized humans' desire for fairness as inequity aversion (e.g., Bolton \& Ockenfels, 2000; Camerer, 2003; Fehr \& Schmidt, 1999; Rabin, 1993). This approach offers a valuable rebuttal to classical models in economics, which view humans as strictly selfish. Analyzing people's behavior in experimental games meant to simulate real-world distributive decisions, researchers have concluded that resource-allocation preferences are not entirely self-interested — but often reflect a desire for equitable outcomes. Importantly, however, behavioral-economic games are typically structured such that equitable outcomes are also equal, as players typically do not differ in their inputs (e.g., Dawes et al., 2007). Thus, many of the findings that have fueled the emphasis on equity in behavioral economics could be interpreted as reflecting a desire for either equity or equality. Disambiguating these possibilities requires researchers to create situations in which the ideals of equity and equality lead to different patterns of distribution.

In practice, disambiguating equity and equality means creating situations in which players' endowments—-the initial amounts they are given to keep or distribute—are not simply "manna from 
heaven" (Cappelen et al., 2007, p. 818). Instead, players must be provided with information about their own and others' inputs. Some work, for instance, has investigated the role of effort in driving people's resource allocations (e.g., Bland et al., 2017; Franco-Watkins et al., 2013; Muehlbacher \& Kirchler, 2009). Franco-Watkins and colleagues (2013) showed that participants compensate most generously those (including themselves) whom they perceive to have expended the greatest effort. Similarly, Muehlbacher and Kichler (2009) found that, if participants earn their endowments by expending more (vs. less) effort, they subsequently contribute fewer resources to the public good-presumably because they feel they deserve to retain more resources for themselves. These findings provide a strong case for the importance of equity in individuals' resource-allocation decisions. However, while equity is undoubtedly important to many participants in studies of this sort, it is still possible that players differ in their responsiveness to equity cues.

In a rare behavioral-economic attempt to document individual differences in fairness ideals, Cappelen and colleagues (2007) designed a dictator game in which the distribution phase (where players decide how much of their money to keep or give away) was preceded by a "production" phase. In the production phase, players were allowed to invest and earn returns on portions of their endowment. While participants could freely decide how much to invest, their subsequent rate of return was determined by luck. The researchers found that $18.4 \%$ of players exhibited "libertarianism," choosing distributions in which all players receive exactly what they earned in the production phase. A larger percentage of players, $38.1 \%$, exhibited "liberal egalitarianism," preferring distributions in which all players retain the amount of their initial investment (over which they had control) irrespective of their rate of return (over which they were powerless). However, the largest group of participants, $43.5 \%$, displayed "strict egalitarianism," selecting equal distributions regardless of the results of the production phase. Thus, when behavioral-economic games are made to better resemble real-world conditions-in which people possess knowledge, or at least credible assumptions, about the sources of their and others' endowments - a plurality of fairness ideals come into view. 


\section{Evolutionary and Comparative Research}

Just as behavioral economists have tended to privilege an equity-based conception of fairness, evolutionary and comparative researchers have typically examined whether human and non-human primates prefer a proportionate ratio of rewards to task demands (e.g., Brosnan \& de Waal, 2003 , 2014; Fehr et al., 2008). Indeed, in their review of research on non-human primates, Bräuer and Hanus (2012) limit their definition of fairness to "an interest in the ideal of equity" and an evolved sense of inequity-aversion. Similarly, in their evolutionary account of the origins of fairness, Debove and colleagues (2017) portray equity as the core of human fairness evaluations. Although Brosnan (2013) suggests that both equality and equity are amenable, in principle, to study in non-human primates, she contends that interpretational challenges make it difficult to distinguish between these fairness ideals in animals.

Definitional issues aside, comparative studies bolster the case for an interest in equity among non-human primates. For instance, it appears that brown capuchin monkeys (Brosnan \& de Waal, 2003) and long-tailed macaques (Massen et al., 2012) may take effort into consideration when judging the fairness of rewards, lending credence to the theory that equity evolved as a means of fostering cooperation between conspecifics. Yet because the animal and evolutionary literature is largely limited to research designs that probe animals' (in)equity considerations (e.g., Proctor et al., 2013), it would be premature to conclude that our recent ancestors lacked concern for equality or need.

\section{Interpersonal vs. Societal Distributions}

Behavioral-economic, comparative, and evolutionary approaches to distributive justice typically share a problematic assumption: that justice reasoning carried out in interpersonal contexts involves the same psychological processes as those used to judge societal distributions. One notable difference between these contexts is that, when deciding which distributions are fair for society as a whole, people lack information about each individual's input—a critical detail usually known to players in economic games and non-human primates in comparative work. Thus, the extent to which we can draw on behavioral economics, or comparative and evolutionary psychology, to understand 
distributive justice at the level of society is unclear. Even if interpersonal justice judgments are governed primarily by equity, it is possible that a greater diversity of principles may be found at the societal level.

Explicitly highlighting the distinction between fairness in interpersonal vs. societal contexts, Starmans and colleagues (2017) conclude that equity underlies fairness judgments and behaviors in both domains. These researchers argue that, to the extent that perceivers take merit to be distributed normally across society—with some individuals being more hard-working and able than others-equality of outcomes is seen as unfair. Conversely, to the degree people view merit as relatively invariant across individuals, an equal distribution of resources will be seen as just. In either case, justice judgments are rooted in perceptions of merit. An implication of this perspective is that even equal distributions may have equity concerns at their root.

Although Starmans and colleagues (2017) note that "outside of the United States and Europe ... there are wide differences in fairness concerns across world cultures" (p. 3) and briefly discuss the possibility that other factors (e.g., need) affect justice perceptions, they conclude that the preference for equitable (i.e., merit-based) outcomes at the societal level is predominant. Similarly, Trump (2020) argues that, within and across societies, people give primacy to equity as the normative rule underlying fair allocations. Thus, recent work treats equity, not as just one of multiple principles of distributive justice, but as the primary basis of human fairness appraisals at the interpersonal and societal levels.

\section{The Diversity of Distributive Justice Beliefs}

In light of the outsize influence of equity theory on psychologists' understanding of prescriptive justice, we believe the time is right to remind our colleagues that equity is just one of several rules that guide human beings' distributive decisions. To this end, we outline evidence that — far from being uniform or universal — justice appraisals are heterogeneous across relationships, developmental stages, cultures, and of particular interest in this article, socioeconomic structures. 


\section{Distributive Justice Across Relationship Types}

Despite the resurgence of emphasis on prescriptive equity beliefs in recent years, older literature in social psychology suggests a diversity of distributive principles across relationship types and their accompanying associational goals. During the heyday of ET, Morton Deutsch (1975) warned that equity-based (as opposed to equality- or need-based) rules of distributive justice are most compatible with cooperative relationships in which the primary goal is economic productivity, rather than welfare or interpersonal harmony and solidarity. Likewise, Sampson (1975) criticizes ET for limiting justice reasoning to the equity principle, arguing for equality as an alternative historical and contemporary solution to the problem of just distributions. He suggests that people's interaction goals, either instrumental in wanting to maximize personal gains, or interpersonal in wanting to create harmonious relationships, are important in identifying which justice rule is applied. Sampson (1975) further proposes that the equality solution underlines cooperative aspects, whereas the equity solution stresses competitive aspects, of relationships. Notably, Sampson (1975, 1983) does not consider equity in human relationships as a natural tendency, but rather as a consequence of political, ideological, and cultural factors - in particular, of Western capitalism. We return to this theme of ideological construction in the empirical portion of this article.

In developing his theory of justice motives, Lerner (1977) differentiates equity and parity (his term for equality) as different forms of justice. He argues that the perceived relationship between the self and others predicts the particular form of justice that is applied in a given situation. In what he calls "unit" relations, the self and other are viewed as similar and the justice of parity prevails. In "non-unit" relations, in which the self and other are viewed as different, the equity rule is applicable (Lerner, 1974). For these early scholars, distributive justice can take forms other than equity—and it is noteworthy that the new wave of researchers who center prescriptive equity (e.g., Graham et al., 2013; Starmans et al., 2017) largely ignore their admonitions against overextending the equity principle.

Alan Fiske $(1992 ; 1991)$ finds that distributive justice, like other life domains, tends to be guided by four distinct relationship types, or what he calls "modes of sociality." Only one of these modes_market pricing — resembles the equity principle. When a social relationship is structured 
according to market pricing, resources are shared according to each member's contribution. Two other forms of sociality in Fiske's formulation, communal sharing and equality matching, more closely parallel the need- and equality modes of distribution, respectively. In communal sharing, group members have the right to share in the resources according to need; in equality matching, resources are shared equally.

Similarly, Miller (2001) argues that different rules of justice must be understood in the context of different forms of human association. His scheme involves three principles of fairness. First, desert (i.e., equity) prevails when people engage in "instrumental association" (coordinated yet self-interested economic activity). Second, equality governs relationships defined by "citizenship" (shared legal and political bonds). Finally, the need principle is predominant for "solidaristic communities" defined by shared culture or beliefs. Although Miller's theory is mostly normative (i.e., concerned with which justice principles are "correct"), he uses empirical data to demonstrate the central role played by these principles, and their corresponding associational forms, in lay conceptions of justice.

Together, these different lines of work suggest that the content of distributive justice is highly dependent upon interaction contexts and the values and goals they foster. In the following section, we review developmental and cross-cultural that the preference for equity-based allocations is a contingent product of socialization and acculturation processes.

\section{Distributive Justice Across Development and Culture}

Developmental psychology has yielded important insights into the diversity of human justice preferences. A robust finding is that, while younger children prefer strict equality in distributions, their preferences become more sensitive to recipients' characteristics-including their merit and needs-over time (e.g., Almås et al., 2010; Essler et al., 2020; Malti et al., 2016; Schmidt et al., 2016. Sigelman \& Waitzman, 1991; Smith \& Warneken, 2016). ${ }^{4}$ In an illustration of this shift, Rizzo and Killen (2016) asked children aged 3 to 8 years to distribute resources between two fictional recipients, one from a poor town and the other from a rich town. Whereas younger children preferred

\footnotetext{
${ }^{4}$ Work using visual preference paradigms has been taken to suggest that infants as young as 20 months possess an understanding of deservingness (Sloane et al., 2012; Surian \& Franchin, 2017). However, some researchers (e.g., Dahl, 2014) have argued that such paradigms fail to illuminate young children's understanding of fairness.
} 
a strictly equal distribution, older children gave more to the poor character-despite the fact neither character had worked harder than the other. Similarly, Kienbaum and Wilkening (2009) found that Swiss and German children between 6 and 9 years of age relied primarily on recipients' levels of need when dividing candies to fictional characters; in this study, it was not until adolescence that children began to incorporate merit into their reasoning. Children's need-based reasoning may be an instantiation of the equality/need rule, in which the goal is to establish "subjective equality" (Cook \& Hegtvedt, 1983; Hochschild, 1981) by meeting individuals' needs.

Evidence suggests that the development of children's of merit- and need-based reasoning does not come at the expense of a preference for strict equality (i.e., identical distributions) in certain situations. Elenbaas (2019), for instance, showed U.S. American children scenarios involving different justice rules_-including merit and equality. Children between 5 and 8 years of age tended to judge scenarios describing use of the equality rule more favorably than scenarios evoking the merit rule. In another study, U.S. American fifth-graders favored equal distributions even in scenarios where recipients' merit was salient (Carson \& Banuazizi, 2008).

Recent work hints at sources of heterogeneity in children and adults' fairness preferences. Although merit-based reasoning is culturally widespread, (Liénard et al., 2013; Zhang, 2020), people from collectivist cultures appear more likely to prefer equal distributions than do people from individualistic cultures. In one study, Chinese adults liked allocators who divided rewards equally more than those who divided rewards equitably (i.e., according to merit) and viewed equal allocations as fairer than equitable ones (Leung \& Bond, 1984). In other work, Huppert and colleagues (2019) had 4- to 11-year-olds from 13 countries play a distributive game. Children were asked to allocate candy to fictional recipients who varied in wealth (amount of candy resources), merit (effort on homework), or elicited empathy (had a broken leg). Children from individualist societies favored equitable distributions when the recipient was high in merit or high in need, whereas children from collectivist cultures preferred equal distributions regardless of recipients' merit or need. In another study, German children distributed proceeds from a joint enterprise according to their and their partner's merit. In contrast, children from a gerontocratic pastoralist 
society in Africa favored highly unequal, yet non-meritocratic, allocations and children from an African hunter-gatherer society in Africa distributed the spoils equally (Schäfer et al., 2015).

A number of issues have yet to be fully addressed in research on children's fairness preferences. First, few studies have examined whether children bring different fairness principles to different resource types. In a rare study of its kind, however, Rizzo and colleagues (2016) found that 6- to 8-year-olds allocated resources necessities based on the need principle, but distributed luxuries according to merit. Another issue when interpreting developmental shifts in children's fairness perceptions concerns the reasoning underlying them. In particular, it is not entirely clear whether children make such decisions based on social norms, feedback from their parents, or genuine moral concerns (Noh, 2020).

Complicating matters further, the contexts in which allocation decisions are made may influence children's preference for unequal distributions. Essler and colleagues (2020), for instance, found that children tended to reference patterns of preexisting inequality in order to justify distributing resources unequally to peers. Cues in the immediate environment, too, can modulate children's behavior in resource allocation tasks. Illustrating this, Ulber and colleagues (2015) found that 18- to 24-month old German dyads often divided resources equally and generously (i.e., unselfishly) — unless possession or ownership cues were made salient by the experimenters. Findings such as these imply that children's justice reasoning is highly context-dependent.

As we have seen, developmental research suggests that equity is just one of several coequal rules governing people's allocation decisions. Children acquire a diversity of fairness intuitions_-including those of strict equality, need (or subjective equality), and merit—none of which appears to wane with age. Moreover, there exists substantial geographic variation in children's and adults' selection of fairness principles in interaction contexts. Such variation implicates factors such as culture, economic organization, and the interaction structures they promote in shaping people's conceptions of distributive justice (Henrich et al., 2005; Hui et al., 1991; Konow et al., 2020). We therefore hypothesize that distributive preferences at the societal level are likewise shaped by experience in a given sociocultural ecology (Kitayama \& Cohen, 2007; Nisbett, 2004). We now turn to an empirical test of this hypothesis. 


\section{Social Institutions and the Construction of Equity Beliefs: The Case of Neoliberalism}

We have argued that people's distributive justice preferences are diverse, varying across development, relationships, economic structures, and cultures. If this is correct, then what processes best explain this rich heterogeneity? Mechanisms based in evolutionary psychology frequently attribute people's social preferences to specific dilemmas faced by our Pleistocene ancestors (Tooby \& Cosmides, 2005). Yet, while evolutionary theorizing can account for the existence of a universal repertoire of justice principles, it cannot easily explain how people in different social milieus come to grant primacy to different principles. Thus, a full account of heterogeneity in people's distributive justice preferences must include learning and acculturative components.

Here we reaffirm psychology's old tradition of viewing justice preferences as ideologies corresponding to particular social goals and motivations. We argue that distributive beliefs reflect, in part, the social structures in which individuals are embedded and the ideologies that those structures communicate. We posit that the beliefs, values, and moral goals of a society are reflected in the social structures that shape the values and morals of its individual members. Hinting at this conclusion, Meindl and colleagues (2019) found that the societal goal of economic power (as opposed to wellbeing of citizens) predicted equity-based (in contrast to equality-based) distributive beliefs. We therefore propose that distributive beliefs be examined in the context of macro-level socioeconomic systems, which collectively form the dominant ideology of an epoch.

\section{The Global Rise of Neoliberalism}

Since the late 1970s, neoliberalism has been the hegemonic economic and social system throughout the world (Crouch, 2020; Harvey, 2007). Neoliberalism typically supports reductions in government spending, privatization of industries, and deregulation to stimulate public consumption and economic growth. Margaret Thatcher, British Prime Minister from 1975 to 1990, undertook massive privatization of previously-public industries (e.g., steel, electricity, gas, oil, coal, and water) and companies (e.g., British Airways and British Telecom)—with the motto "There is no alternative [to free-market capitalism].” During the same period, U.S. President Ronald Reagan instituted 
"Reaganomics," which greatly decreased government social spending and federal regulation of industry through laws such as the Economic Recovery Tax Act of 1981 and the Reform Act of 1986. In China, after the death of Mao Zedong in 1976, Deng Xiaoping enacted the Chinese version of neoliberalization through a program of economic reform, which included de-collectivization of agriculture and the opening of the country's markets to foreign investment. Chilean dictator Augusto Pinochet, after his military takeover in 1973, experimented with neoliberalism by deregulating capital flow, reducing taxes, and suppressing labor unions. International financial institutions such as the International Monetary Fund (IMF) and World Bank adopted neoliberal policies in the early 1980s and played a large role in spreading them globally_especially in the Global South through Structural Adjustment Programs (SAPs).

Neoliberalism's manifestations have varied from country to country, and each case has its own peculiarities. Nevertheless, neoliberalism's general framework reaches beyond historically free-market economies in the Western hemisphere and has transformed many societies around the world - including traditional social democracies such as Sweden and ostensibly anticapitalist states such as China (Harvey, 2007; Saad Filho \& Johnston, 2004). Moreover, neoliberalism has not only permeated national and international discourse, policies, and institutions, but is also reflected in values and beliefs about individual effort, merit, and deservingness (G. Adams et al., 2019; Brown, 2019). Thatcher herself admitted this transformation when she proclaimed, "Economics are the method, but the object is to change the soul." Our empirical goal in the present paper is to document the impact of neoliberal economic "methods" on individuals' "souls" - that is, people's conceptions of fairness and distributive justice. Doing so promises both to illuminate the psychological effects of the global economic order and make an affirmative case that individuals' distributive preferences are actively constructed through social and economic structures.

\section{Meritocracy, Neoliberalism, and the Ideological Basis of Equity Beliefs}

The psychological dimensions of neoliberalism-in particular, the individual beliefs and values that reflect and sustain it—have recently become a focus of psychological study (Bettache \& Chiu, 2019). At the center of neoliberal subjectivity are descriptive and prescriptive equity (Bay- 
Cheng et al., 2015; Beattie et al., 2019; Grzanka et al., 2020). Adams and colleagues (2019) argue that, among other psychological effects, neoliberalism enforces an "individualist-entrepreneurial" understanding of the self. Individualist-entrepreneurial selfways abstract the person from the restraints of context and view the self as autonomous from its social and material surroundings. As Thatcher once declared, "They [people in economic need] are casting their problems on society and who is society? There is no such thing! There are individual men and women."

When applied to the economic domain, neoliberalism's individualist-entrepreneurial selfways naturally foster prescriptive meritocracy. By casting individuals as free agents whose successes and failures reflect their own choices, neoliberalism encourages the belief that societal benefits and burdens ought to be allocated in proportion to individuals' contributions to the collective. Yet this formulation does not by itself establish proportionality as a moral principle; indeed, other considerations, such as economic efficiency and growth, might justify calibrating individuals' outcomes to their "inputs." However, as Michael Sandel (2020) notes in his critique of meritocracy, proponents of neoliberalization-from Reagan to Thatcher to Bill Clinton-have always tied neoliberalism's mandate of proportional rewards to moralized notions of deservingness. For such leaders, neoliberalism's promise of proportionality ensures that people "get what they deserve and deserve what they get." At a more fundamental level, Fourcade and Healy (2007) argue that economic principles, when promulgated to society as a whole, represent "moralized projects" that inevitably mold laypeople's understanding of what is and is not fair. Thus, neoliberalism (at least in its Western incarnations) is inextricably linked to prescriptive equity-the notion that deviations from the proportional allocation of burden and benefits are unjust.

\section{Has Neoliberalism Shaped Distributive Beliefs? An Empirical Investigation}

Psychological theorizing suggests an intimate connection between neoliberal systems and individuals' distributive justice beliefs. On this view, equity beliefs are ideological products arising from exposure to decentralized and deregulated economic structures (and their associated moral rhetorics; Sandel, 2020) that idealize individuals as free agents who ought to incur proportional rewards and burdens. Our empirical goal was to test this process of ideological construction. To this 
end, we investigated the relationship between neoliberal economic structures and prescriptive distributive justice beliefs_-in particular, preference for equal vs. merit-based income distributions-in more than 160 countries over the past two decades.

\section{Datasets and Variables}

Neoliberal policies were measured using the Fraser Institute's 42-item "Economic Freedom Index" (EFI). The Fraser Institute is a conservative think tank that began issuing the EFI in 2000, and since then has provided a yearly score for over 160 countries. (For the 1970-1999 period, the Fraser Institute compiled retrospective EFI scores in five-year increments.) The most recent publicly-available dataset contains EFI scores for as late as 2019 (https://www.fraserinstitute.org/studies/economic-freedom). The Fraser Institute items fall into five groups, labeled "Size of government," "Legal structure and property rights," "Sound money," "Freedom to trade internationally," "Regulation of business, credit, and labor"; the institute provides an average for each group as well as an aggregate measure (labeled EFI).

A psychometric study of the 42 items of the EFI has identified a four-factor structure (DePhillips, 2015). According to DePhillips (2015), three of the factors, representing economic development, trade openness, and monetary stability, tap into traditional liberalism. The fourth factor captures neoliberalism. Items that load on this factor include the following: government consumption, transfers and subsidies, top marginal income tax, income and payroll tax, hiring and firing regulation, centralized collective bargaining, regulation of work hours, and administrative requirements. Higher scores on this index indicate higher levels of neoliberalism.

Our measure of distributive justice came from the World Values Survey (WVS; Inglehart et al., 2014). Our analysis was conducted on five waves of data, from WVS wave 3 (1995-1998) through 7 (2017-2019). 5 The following item was used to gauge distributive fairness preferences: "How would you place your views on this scale? 1 means you agree completely with the statement on the left; 10 means you agree completely with the statement on the right; and if your views fall

\footnotetext{
${ }^{5}$ WVS recruits random probability representative samples of the adult population. In wave 7 (2017-2020), data were collected in 50 countries $(n=69,578)$. In wave $6(2010-2014)$ data were collected in 60 countries $(n=89,564)$. In wave 5 (2005-2009) data were collected in 58 countries $(n=83,975)$. In wave $4(1999-2004)$ data were collected in 41 countries $(n=60,040)$. In wave $3(1995-1998)$ data were collected in 54 countries $(n=77,818)$.
} 
somewhere in between, you can choose any number in between." On the left, the statement "Incomes should be made more equal" appeared, and on the right the statement "We need larger income differences as incentives for individual effort" appeared. Therefore, higher numbers indicated preference for merit-based (vs. equal) income distributions (1981-2019 time-series WVS dataset can be found at https://www.worldvaluessurvey.org/WVSDocumentationWVL.jsp).

We also included two time-varying covariates, the Human Development Index (HDI) and the Gini index, to adjust for differences in economic "development" and inequality, respectively, between countries. The HDI encompasses the dimensions of life expectancy, educational attainment, and gross national income (GNI) per capita, and the scores for these three facets are averaged into a composite index. The Gini index measures the extent to which the distribution of income in a society differs from perfectly equality; Gini scores were obtained from the World Bank website (https://data.worldbank.org/indicator/SI.POV.GINI).

In a secondary analysis, we included a WVS item used in previous research to measure individualism-collectivism (Santos et al., 2017)—specifically, the percentage of respondents in a country who said that it was important to teach children the value of independence. This item presents a list of qualities "that children can be encouraged to learn at home," and respondents are asked to indicate up to five qualities that they consider to be especially important to teach children. Among the listed qualities is "independence." Responses are dichotomized for each quality, such that $1=$ important and $0=$ not mentioned. Following Santos et al. (2017), we calculated the percentage of people who mentioned "independence" in each country and in each wave to create our index of individualism.

\section{Primary Analysis}

To merge the EFI and WVS datasets, we first averaged our index of neoliberalism (the neoliberalism subfactor of the EFI) across the years containing each WVS wave. Therefore, our final dataset contained five measurement occasions for neoliberalism and distributive justice beliefs (wave $1=1995-1998$, wave $2=1999-2004$, wave $3=2005-2009$, wave $4=2010-2014$, wave $5=$ 
2017-2019) ${ }^{6}$ We used bivariate Dynamic Structural Equation Modeling (DSEM; Asparouhov et al., 2018; McNeish \& Hamaker, 2020) to estimate parameters in Mplus 8.5 (Muthén \& Muthén, 2017). In DSEM, data is decomposed into time-variant (within-cluster) and time-invariant (between-cluster) components. The time-invariant component represents constructs' stable means (or fixed effect in the multilevel framework), while the time-varying component models deviations from these means (or random effects in the multilevel framework). DSEM uses a Bayesian algorithm and estimates parameters using a Markov chain Monte Carlo (MCMC) procedure. We used the fbiter option in Mplus to set the number of iterations to 10,000 . With this option, the posterior distribution is based on the last half of the iterations (the last 5,000 in our model).

We monitored convergence by tracking the potential scale reduction factor (PSRF; Brooks $\&$ Gelman, 1998) and examining trace and autocorrelation plots of the parameter estimates (Asparouhov et al., 2018; McNeish \& Hamaker, 2020). In order to obtain relatively independent draws from the posterior distribution of the parameters, we specified the thin option to request that only every tenth iteration of the parameter be kept. We used the default "diffuse" priors in Mplus indicating that the results are driven only by the data with no prior assumptions. Finally, we used the tinterval option to account for the uneven spacing of the observations.

In Model 1, neoliberalism and individuals' distributive beliefs for country $i$ at time $t$ are predicted from neoliberalism and beliefs at the preceding measurement occasion $(t-1)$. Both neoliberal policies and distributive beliefs are latently centered around their country means. We also included time-varying HDI and Gini in the model; therefore, neoliberalism and individuals' distributive beliefs for country $i$ at time $t$ are predicted from neoliberalism and beliefs at the preceding measurement occasion $(t-1)$ while adjusting for HDI and Gini at time $t$. (For the annotated Mplus code for Model 1, see Appendix A or the study's OSF page.) The Model 1 equations are:

\footnotetext{
${ }^{6}$ Including all 7 waves of the WVS does not change our conclusions. However, given the small sample size of the first 2 WVS waves, we sought to obtain more stable parameter estimates by including only the last 5 waves in our analyses.
} 


\section{Within-country Equations}

$$
\begin{aligned}
\text { Equity }_{t i} & =\alpha_{1 i}+\phi_{1 i} \text { Equity }_{(t-1) i}+\phi_{4 i} \operatorname{Neolib}_{(t-1) i}+\beta_{1 i} \operatorname{Gini}_{t i}+\beta_{2 i} \mathrm{HDI}_{t i}+e_{1 t i} \\
\text { Neolib }_{t i} & =\alpha_{1 i}+\phi_{2 i} \operatorname{Neolib}_{(t-1) i}+\phi_{3 i} \text { Equity }_{(t-1) i}+e_{1 t i}
\end{aligned}
$$

\section{Between-country Equations}

$$
\begin{aligned}
\alpha_{1 i} & =\gamma_{00}+u_{0 i} \\
\alpha_{2 i} & =\gamma_{10}+u_{1 i} \\
\phi_{1 i} & =\gamma_{20}+u_{2 i} \\
\phi_{2 i} & =\gamma_{30}+u_{3 i} \\
\phi_{3 i} & =\gamma_{40}+u_{4 i} \\
\phi_{4 i} & =\gamma_{50}+u_{5 i} \\
\beta_{1 i} & =\gamma_{60}+u_{6 i} \\
\beta_{2 i} & =\gamma_{70}+u_{7 i}
\end{aligned}
$$

In this model, the country-specific residual variances for each outcome are

$$
\begin{aligned}
& \sigma_{1 i}^{2}=\exp \left(\omega_{0}+u_{8 i}\right) \\
& \sigma_{2 i}^{2}=\exp \left(\omega_{1}+u_{9 i}\right)
\end{aligned}
$$

where $e_{1 t i} \sim \mathrm{N}\left(0, \sigma_{1 i}^{2}\right)$ and $e_{2 t i} \sim \mathrm{N}\left(0, \sigma_{2 i}^{2}\right)$

The latent covariance of residual variances, $\sigma_{1 i 2}^{2}$ and $\sigma_{i 2}^{2}$ was specified to be positive, and its mean (fixed part) and variance (random part) are denoted by $\eta$ and $\rho$, respectively, in Table 1. Except for the positive covariance between the residual variances, all other latent random variables were specified to have zero correlation with one another. Within- and between-country models are depicted in Figures $1 \mathrm{~A}$ and $1 \mathrm{~B}$, respectively.

\section{Primary Results}

Full results for the analysis are shown in Table 1. See Figure 2 for a depiction of standardized estimates and $95 \%$ credible intervals (CIs) for the primary coefficients of interest (i.e., the crosslagged and autoregressive effects). 


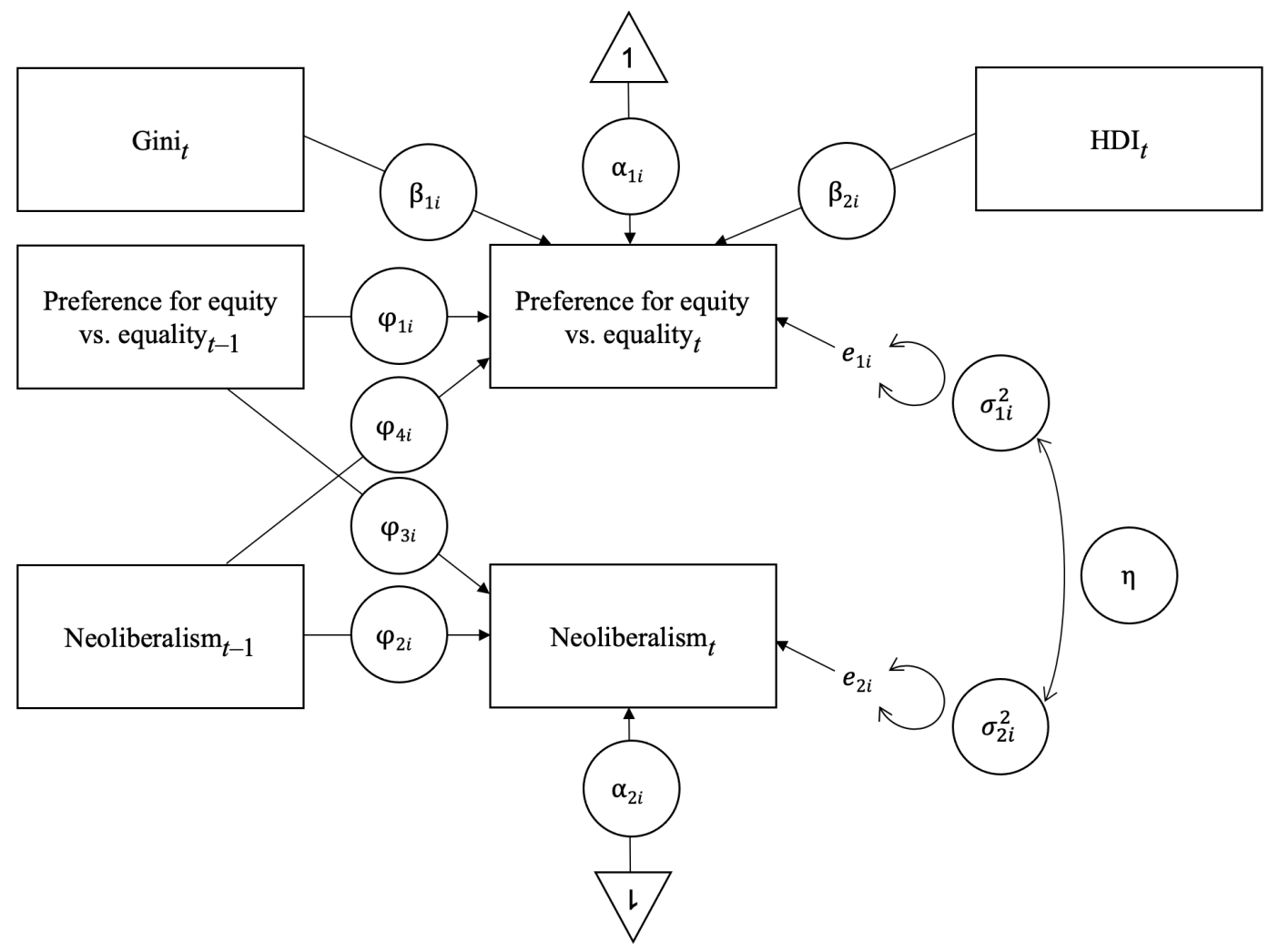

(a) Within-country Model

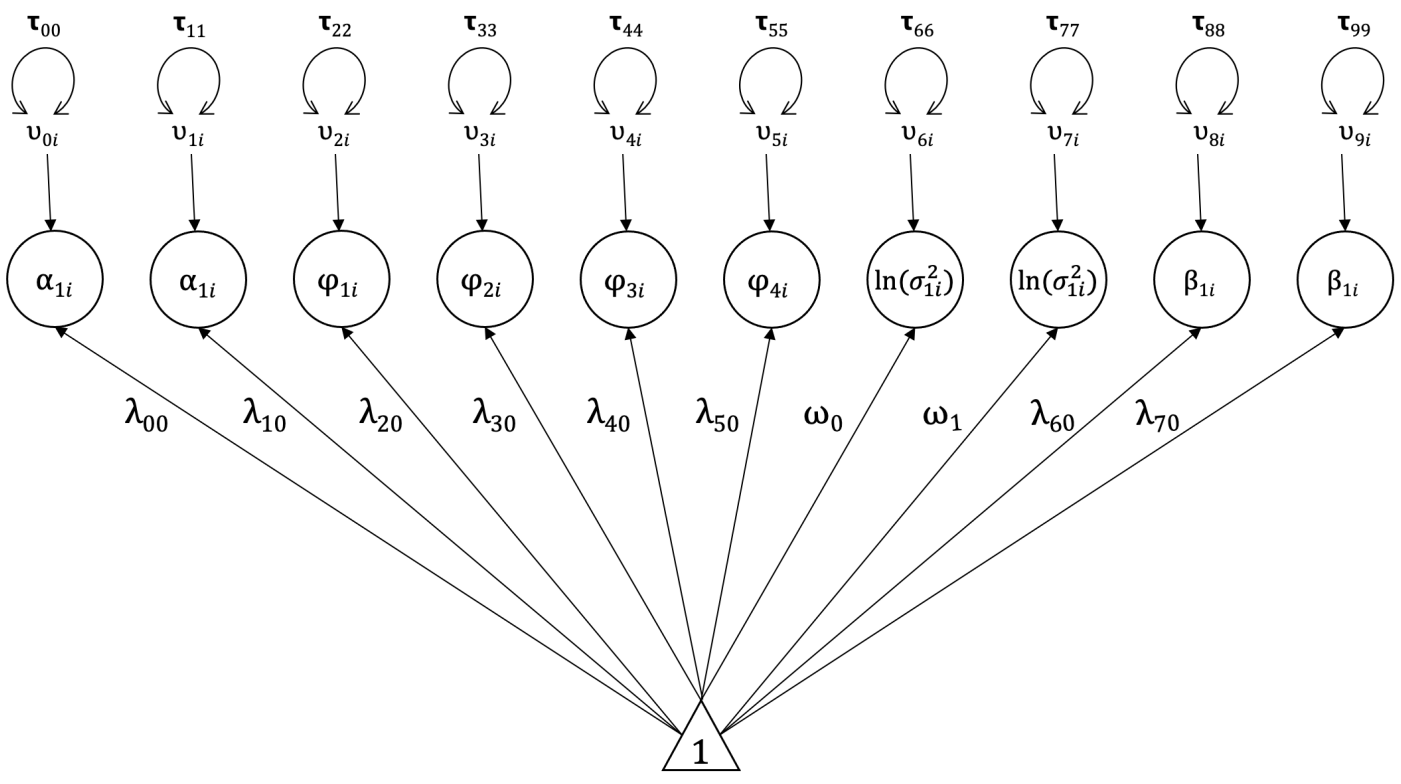

(b) Between-country Model

Figure 1: Primary Model 
Table 1: Estimates and 95\% Credible Intervals (CIs) for Primary Model

\begin{tabular}{|c|c|c|c|c|c|c|}
\hline & \multicolumn{3}{|c|}{ Fixed Effects (Means) } & \multicolumn{3}{|c|}{ Random Effects (Variances) } \\
\hline & Notation & Estimate & $95 \% \mathrm{CI}$ & Notation & Estimate & $95 \% \mathrm{CI}$ \\
\hline \multicolumn{7}{|l|}{ Intercepts } \\
\hline$\alpha_{1}$ : Equity $_{t}$ & $\gamma_{00}$ & 5.94 & {$[5.74,6.15]$} & $\tau_{00}$ & .36 & {$[.06, .66]$} \\
\hline$\alpha_{2}:$ Neoliberalism $_{t}$ & $\gamma_{10}$ & 6.72 & {$[6.46,6.95]$} & $\tau_{11}$ & .15 & {$[0.01, .52]$} \\
\hline \multicolumn{7}{|l|}{ Autoregressive effects } \\
\hline$\phi_{1}:$ Equity $_{t-1} \rightarrow$ Equity $_{t}$ & $\gamma_{20}$ & -.028 & {$[-.29, .26]$} & $\tau_{22}$ & .07 & {$[.01, .20]$} \\
\hline$\phi_{2}:$ Neoliberalism $_{t-1} \rightarrow$ Neoliberalism $_{t}$ & $\gamma_{30}$ & .81 & {$[.75, .87]$} & $\tau_{33}$ & .01 & {$[.003, .03]$} \\
\hline \multicolumn{7}{|l|}{ Cross-lagged Effects } \\
\hline$\phi_{3}:$ Equity $_{t-1} \rightarrow$ Neoliberalism $_{t}$ & $\gamma_{40}$ & -.06 & {$[-.17, .06]$} & $\tau_{44}$ & .04 & {$[.003, .13]$} \\
\hline$\phi_{4}:$ Neoliberalism $_{t-1} \rightarrow$ Equity $_{t}$ & $\gamma_{50}$ & .24 & {$[.11, .40]$} & $\tau_{55}$ & .02 & {$[.002, .10]$} \\
\hline \multicolumn{7}{|l|}{ Concurrent Effects } \\
\hline$\beta_{1}:$ Gini $_{t-1} \rightarrow$ Equity $_{t}$ & $\gamma_{60}$ & .03 & {$[-.03, .09]$} & $\tau_{66}$ & .004 & {$[.001, .02]$} \\
\hline$\beta_{2}: \mathrm{HDI}_{t-1} \rightarrow$ Equity $_{t}$ & $\gamma_{70}$ & -2.75 & {$[-6.19, .92]$} & $\tau_{77}$ & 31.12 & {$[1.37,108.89]$} \\
\hline \multicolumn{7}{|l|}{ Log Residuals } \\
\hline Equity $_{t} \log$ residual variance & $\omega_{0}$ & -.88 & {$[-1.58,-.40]$} & $\tau_{88}$ & .45 & {$[.06,1.64]$} \\
\hline Neoliberalism $_{t} \log$ residual variance & $\omega_{1}$ & -2.90 & {$[-3.83,-2.19]$} & $\tau_{99}$ & 1.22 & {$[.19,2.35]$} \\
\hline Covariance of residual variances & $\eta$ & -1.65 & {$[-2.17,-1.24]$} & $\rho$ & .24 & {$[.01, .86]$} \\
\hline
\end{tabular}

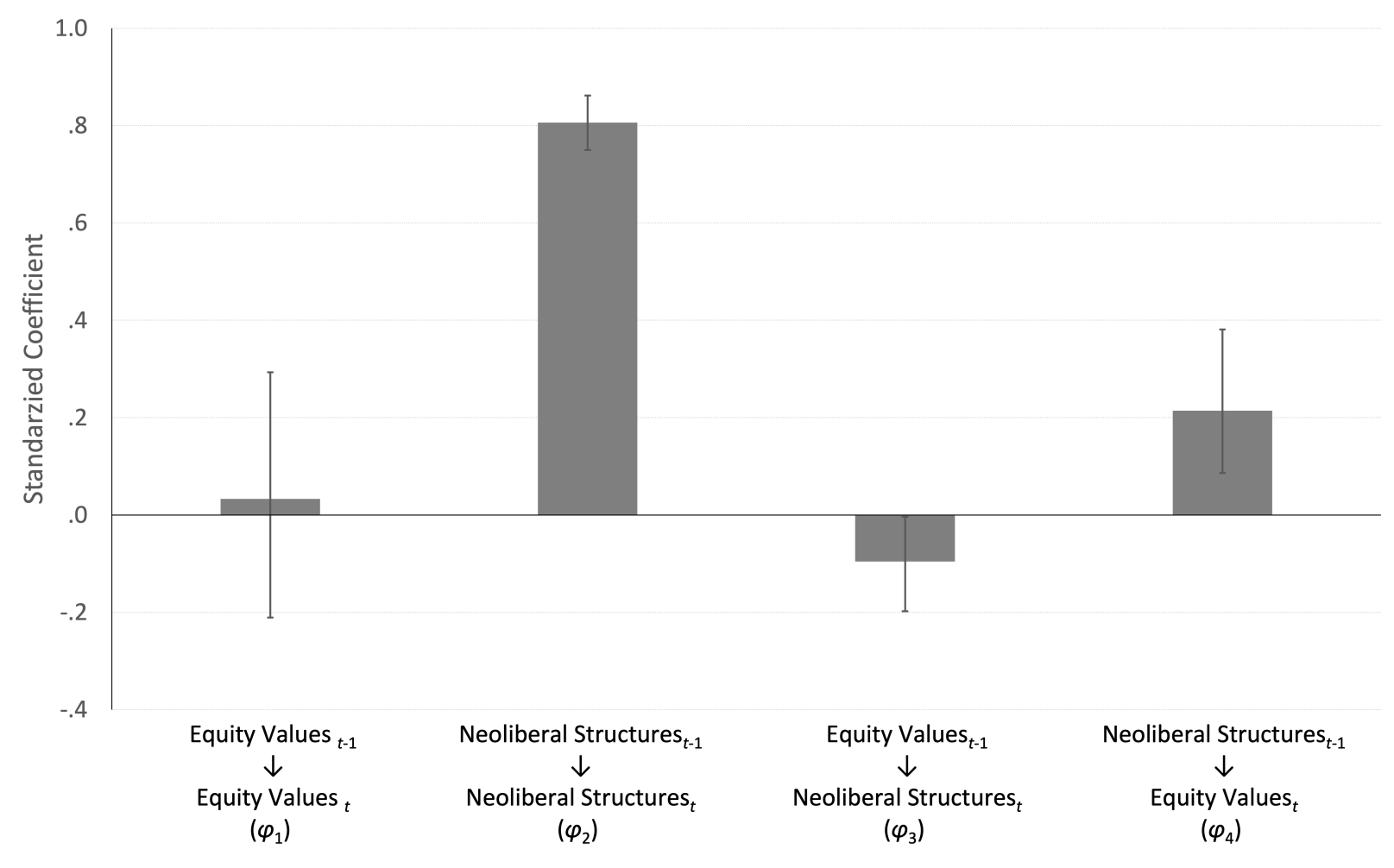

Figure 2: Standardized Coefficients for Autoregressive and Cross-lagged effects in the Primary Model 
Convergence Trace plots and autocorrelation plots of the main parameters of interest from Model 1 are included in Appendix B. Inspection of these plots confirmed that the model successfully converged. Of the 28 estimated parameters, 22 parameters had a PSR equal to 1.01.

Autoregressive (Lagged) Effects Lag-1 equity preferences did not predict preferences at time $t$ $\left(\phi_{1 i}\right)$, Lag-1 neoliberalism positively predicted neoliberalism at time $t\left(\phi_{2 i}\right)$, adjusting for HDI and Gini. The CI around the mean of of $\left(\phi_{1 i}\right)$ excludes zero, but the CI for the mean of $\phi_{2 i}$ contains zero.

Crossed-Lagged Effects Lag-1 neoliberalism predicted higher equity preferences at time $t\left(\phi_{4 i}\right)$, whereas Lag-1 beliefs did not predict neoliberalism at time $t\left(\phi_{3 i}\right)$, adjusting for the time-varying effects of HDI and Gini. The CI around the mean of $\phi_{4 i}$ excludes zero, whereas the CI around the mean $\phi_{3 i}$ contains zero.

\section{Secondary Analysis}

Next, we examined whether individualism is, as theorized in previous literature (e.g., G. Adams et al., 2019), related to the effects we estimated. We thus ran an additional model, including our indicator of individualism as a time-invariant $7^{7}$ Therefore, we could not further investigate the concurrent effect of individualism on equity beliefs. covariate in the model (Model 2). Including the time-invariant effect of individualism allowed us to investigate whether the cross-lagged effect of neoliberalism on equity beliefs $\left(\phi_{4 i}\right)$ could be predicted by the fixed (grand-mean centered) effect of individualism (effect denoted by $\gamma_{51}$ ). The Model 2 equations are:

\section{Within-country Equations}

$$
\begin{aligned}
& \text { Equity }_{t i}=\alpha_{1 i}+\phi_{1 i} \text { Equity }_{(t-1) i}+\phi_{4 i} \operatorname{Neolib}_{(t-1) i}+e_{1 t i} \\
& \text { Neolib }_{t i}=\alpha_{1 i}+\phi_{2 i} \operatorname{Neolib}_{(t-1) i}+\phi_{3 i} \text { Equity }_{(t-1) i}+e_{1 t i}
\end{aligned}
$$

\footnotetext{
${ }^{7}$ We also ran a model with time-varying individualism as a covariate, but this model failed to converge. Therefore, we could not further investigate the concurrent effect of individualism on equity beliefs.
} 


\section{Between-country Equations}

$$
\begin{aligned}
\alpha_{1 i} & =\gamma_{00}+\gamma_{01} \text { Individualism }_{c}+u_{0 i} \\
\alpha_{2 i} & =\gamma_{10}+\gamma_{11} \text { Individualism }_{c}+u_{1 i} \\
\phi_{1 i} & =\gamma_{20}+\gamma_{21} \text { Individualism }_{c}+u_{2 i} \\
\phi_{2 i} & =\gamma_{30}+\gamma_{31} \text { Individualism }_{c}+u_{3 i} \\
\phi_{3 i} & =\gamma_{40}+\gamma_{41} \text { Individualism }_{c}+u_{4 i} \\
\phi_{4 i} & =\gamma_{50}+\gamma_{51} \text { Individualism }_{c}+u_{5 i}
\end{aligned}
$$

In this model, the country-specific residual variances for each outcome are

$$
\begin{aligned}
& \sigma_{1 i}^{2}=\exp \left(\omega_{0}+\omega_{2}+u_{6 i}\right) \\
& \sigma_{2 i}^{2}=\exp \left(\omega_{1}+\omega_{3}+u_{7 i}\right)
\end{aligned}
$$

where $e_{1 t i} \sim \mathrm{N}\left(0, \sigma_{1 i}^{2}\right)$ and $e_{2 t i} \sim \mathrm{N}\left(0, \sigma_{2 i}^{2}\right)$

The subscript $c$ for individualism specifies that individualism is grand-mean centered across countries. The latent covariance between residual variances $\sigma_{1 i 2}$ and $\sigma_{2 i 2}$ was specified to be positive, and its mean (fixed part) and variance (random part) are denoted by $\eta$ and $\rho$, respectively, in Table 2 . As in the previous model, aside from the positive covariance between the residual variances, all other latent random variables were specified to have zero correlation with each other.

\section{Secondary Results}

See Table 2 for full model results.

Convergence In Model 2, using the percentage of people within a country who reported "independence" to be an important quality to teach children as the measure of individualism, six parameters had a PSR equal to 1.083. The autocorrelation and trace plots of the main parameters of interest (mean and variance of $\phi_{4}$ ) suggested satisfactory convergence (See Appendix B).

Autoregressive (Lagged) Effects Lag-1 distributive preferences did not predict preferences at time $t$ ( 0 is inside the CI for the mean of $\left.\phi_{1 i}\right)$. However, Lag-1 neoliberalism positively predicted neoliberalism at time $t$ ( 0 falls outside of the CI for the mean of $\phi_{2 i}$ ). 
Table 2: Estimates and 95\% Credible Intervals (CIs) for Secondary Model

\begin{tabular}{|c|c|c|c|c|c|c|}
\hline & \multicolumn{3}{|c|}{ Fixed Effects (Means) } & \multicolumn{3}{|c|}{ Random Effects (Variances) } \\
\hline & Notation & Estimate & $95 \% \mathrm{CI}$ & Notation & Estimate & $95 \% \mathrm{CI}$ \\
\hline \multicolumn{7}{|l|}{ Intercepts } \\
\hline$\alpha_{1}$ : Equity $_{t}$ & $\gamma_{00}$ & 5.93 & {$[5.73,6.14]$} & $\tau_{00}$ & .25 & {$[.05, .57]$} \\
\hline$\alpha_{2}:$ Neoliberalism $_{t}$ & $\gamma_{10}$ & 6.67 & {$[6.39,6.93]$} & $\tau_{11}$ & .19 & {$[.02, .58]$} \\
\hline \multicolumn{7}{|l|}{ Autoregressive effects } \\
\hline$\phi_{1}:$ Equity $_{t-1} \rightarrow$ Equity $_{t}$ & $\gamma_{20}$ & .11 & {$[-.18, .36]$} & $\tau_{22}$ & .06 & {$[.001, .19]$} \\
\hline$\phi_{2}:$ Neoliberalism $_{t-1} \rightarrow$ Neoliberalism $_{t}$ & $\gamma_{30}$ & .81 & {$[.75, .86]$} & $\tau_{33}$ & .01 & {$[.001, .02]$} \\
\hline \multicolumn{7}{|l|}{ Cross-lagged Effects } \\
\hline$\phi_{3}:$ Equity $_{t-1} \rightarrow$ Neoliberalism $_{t}$ & $\gamma_{40}$ & -.07 & {$[-.18, .04]$} & $\tau_{44}$ & .03 & {$[.002, .12]$} \\
\hline$\phi_{4}:$ Neoliberalism $_{t-1} \rightarrow$ Equity $_{t}$ & $\gamma_{50}$ & .18 & {$[.06, .33]$} & $\tau_{55}$ & .02 & {$[.001, .09]$} \\
\hline \multicolumn{7}{|l|}{ Mean Individualism Effects } \\
\hline Individualism $_{c} \rightarrow \phi_{1}$ & $\gamma_{21}$ & .02 & {$[-.13, .15]$} & & & \\
\hline Individualism $_{c} \rightarrow \phi_{2}$ & $\gamma_{31}$ & -.05 & {$[-.08,-.01]$} & & & \\
\hline Individualism $_{c} \rightarrow \phi_{3}$ & $\gamma_{41}$ & -.02 & {$[-.09, .05]$} & & & \\
\hline Individualism $_{c} \rightarrow \phi_{4}$ & $\gamma_{51}$ & -.05 & {$[-.13, .03]$} & & & \\
\hline Individualism $_{c} \rightarrow$ Equity $_{t}$ & $\gamma_{01}$ & .03 & {$[-.12, .18]$} & & & \\
\hline Individualism $_{c} \rightarrow$ Neoliberalism $_{t}$ & $\gamma_{11}$ & .04 & {$[-.20, .29]$} & & & \\
\hline Individualism $_{c} \rightarrow$ Equity $_{t} \log$ res var & $\omega_{2}$ & .11 & {$[-.09, .33]$} & & & \\
\hline Individualism $_{c} \rightarrow$ Neoliberalism $_{t} \log$ res var & $\omega_{3}$ & .30 & {$[-.21, .69]$} & & & \\
\hline \multicolumn{7}{|l|}{ Log Residuals } \\
\hline Equity $_{t} \log$ residual variance & $\omega_{0}$ & -.53 & {$[-.96,-.14]$} & $\tau_{66}$ & .32 & {$[.03,1.06]$} \\
\hline Neoliberalism $_{t} \log$ residual variance & $\omega_{1}$ & -2.89 & {$[-4.51,-2.12]$} & $\tau_{77}$ & .97 & {$[.07,2.21]$} \\
\hline Covariance of residual variances & $\eta$ & -1.56 & {$[-2.06,-1.16]$} & $\rho$ & .25 & {$[.01, .73]$} \\
\hline
\end{tabular}

Cross-Lagged Effects As in Model 1, Lag-1 neoliberalism in Model 2 predicted higher equitybased distributive preferences at time $t\left(\phi_{4 i}\right)$, whereas Lag-1 equity preferences did not predict neoliberalism at time $t\left(\phi_{3 i}\right)$.

Time-invariant Effects of Individualism The time-invariant effects of individualism on the fixed and random effect of interest $\left(\phi_{4 i}\right)$ were not different from zero. Individualism did, however, predict the autoregressive effect of neoliberalism $\left(\phi_{2 i}\right)$, such that the higher a country's level of individualism, the weaker the relationship between neoliberalism at successive timepoints. No other effects of individualism emerged. 


\section{Discussion}

To summarize our findings, data from more than 160 countries collected in the past two decades suggest that neoliberal systems have been instrumental in promoting equity-based distributive beliefs, shifting the emphasis from the equality principle to the merit principle. At a broad level, our analysis suggests that equity beliefs, and distributive justice more broadly, should be understood with respect to the socioeconomic context and the ideological hegemony of the era within which they are studied, and not merely by resorting to universalistic notions of distributive justice.

An important issue when using dynamic longitudinal models is whether the time interval specified in the analysis is appropriate to model the theorized processes (Voelkle et al., 2018). Here, our five measurement occasions were 1995-1998 (wave 1), 1999-2004 (wave 2), 2005-2009 (wave 3), 2010-2014 (wave 4), and 2017-2019 (wave 5). Since WVS measurement continues for five years and not every country is measured at the same time, we can only speak of the average number of years between measurement occasions, which is roughly four years. Thus, our analysis assumes that a period of approximately four years is long enough for neoliberal policies and institutions to influence justice beliefs within societies (and conversely, for equity beliefs to shape neoliberal systems). Our results, in which higher than average (within-country) levels of neoliberalism tend to be followed by higher than average (within-country) levels of belief in equity, suggest that four years is sufficient for-as Thatcher put it—systems to change "souls." Conversely, the fact we did not find an effect of equity beliefs on neoliberal policies may suggest that four years is not long enough for "souls" to change systems.

The literature offers few clues as to how long it might take for values, attitudes, and behaviors at the individual level to shape socioeconomic and governmental institutions. In one relevant paper, however, Donni and Marino (2020) used a dynamic analytic strategy similar to ours to model the relationship between collective action and institutional change. These researchers found that collective action (proxied by the occurrence of anti-government demonstrations, strikes, riots and revolutions) was not related to "democratic consolidation"- that is, the continued existence of democratic institutions a year ${ }^{8}$ later. (Collective action did, however, predict the emergence of

\footnotetext{
${ }^{8}$ Donni and Marino (2020) found similar results when modeling three- and five-year lagged effects.
} 
democracy in formerly autocratic states.) Donni and Marino's (2020) findings suggest that it may take more than a couple of years for individuals' attitudes and behaviors to shape institutional structures (at least in preexisting democracies). This comports with the present results suggesting that, if individuals' distributive beliefs shape intuitions at all, such a process may require more than a few years to play out.

The results involving individualism deserve further consideration. Model 2 yielded no significant effects of countries' mean levels of individualism on the cross-lagged parameters $\left(\phi_{3}\right.$ and $\left.\phi_{4}\right)$. Thus, we see no evidence that individualism moderates the effect of neoliberalism on equity values or of equity values on neoliberalism. Neither did the model reveal "main effects" of individualism on equity $\left(\gamma_{01}\right)$ or neoliberalism $\left(\gamma_{11}\right)$. These null results may appear to contradict prevailing ideas concerning the construction of individualist-entrepreneurial selfways in neoliberal societies (e.g., G. Adams et al., 2019). However, a closer examination of the literature resolves this apparent contradiction. Individualism and collectivism involve a "horizontal" type emphasizing equality and "vertical" type emphasizing hierarchy (Singelis et al., 1995). While horizontal individualism (HI) involves self-reliance, independence, and need for uniqueness, vertical individualism (VI) values competition and status. Neoliberal subjectivity and its constituent entrepreneurial-individualist selfway (emphasizing competition, merit, and hierarchy) may therefore be more closely aligned with VI. Because our measure of individualism from the WVS (independence values) measures HI, it is not surprising that we failed to observe effects of individualism on equity, neoliberalism, or the cross-lagged parameters connecting these variables.

At the same time, a significant relationship emerged between countries' mean levels of individualism and the autoregression parameter for neoliberalism $\left(\phi_{2}\right)$ - such that highly individualistic nations displayed smaller autoregressions. While we are reluctant to overinterpret this effect, we can speculate on its meaning. The $\phi_{2}$ autoregression reflects the degree to which a country's current neoliberalism can be predicted from its past neoliberalism - and thus can be thought of as the amount of institutional inertia characterizing the country. Countries with large neoliberalism autoregressions displayed high levels of institutional stability; those with small autoregressions changed more rapidly from survey wave to survey wave. The question, then, is why 
highly (horizontally) individualistic countries would display less institutional inertia (i.e., more rapid variation in neoliberal structuring over time). We believe the answer may be found in the the values underlying horizontal individualism. Specifically, individualism (at least in its horizontal configuration) consists of self-direction and stimulation values - that is, the prioritization of creativity and novelty, respectively (Schwartz, 1990). Collectivism (Singelis et al., 1995), particularly in its vertical form, encompasses security and tradition values, which reflect the desire for societal stability and preservation of the status quo (Schwartz, 1990). Countries in which political elites and laypeople emphasize change-friendly individualistic values may initiate and tolerate more frequent alterations to institutional arrangements than do societies whose members value more change-averse collectivistic values. While this interpretation is tentative, the observed effect of individual-level individualism is just the sort of micro/macro-spanning relationship between values and structures that we believe deserve more psychological study.

\section{Conclusions}

In this article, we reviewed psychological literature from social, developmental, and cultural psychology to argue that, contrary to prevailing conceptions of distributive justice, the preference for equity is neither universal nor homogeneous. Specifically, we amplify the proposition of our discipline's pioneers that the equity principle is only one of the justice rules people apply in making distributive judgments. We further argue that distributive justice beliefs are ideological formations, shaped in the context of corresponding social, economic, and political structures and institutions. We support this argument by analyzing longitudinal relationships between neoliberal structures and individuals' equity preferences in more than 160 countries over 24 years. Our results suggests that neoliberalism has played a key role in shifting distributive justice beliefs from a preference for equality to a preference for merit.

The extant literature in psychology conceptualizes neoliberalism as a belief system that can vary dispositionally and situationally (Beattie et al., 2019; Bettache \& Chiu, 2019). Bay-Cheng and colleagues (2015) developed a Neoliberal Beliefs Inventory (NBI), which taps four sub-facets of neoliberal thinking: System Inequality, conceptualized as views about the existence and the 
extent of inequality in society; Competition, measuring the extent to which one views competition as natural and beneficial; Personal Wherewithal, defined as attributing outcomes and success to personal dispositions such as hard work and merit; and Government Interference, gauging the extent to which state intervention is seen to constrain personal freedom and endanger the meritocratic ideal. In another attempt, Grzanka and colleagues (2020) created the single-facet Anti-Neoliberal Attitudes Scale (ANAS) scale using items from existing inventories. Moreover, the endorsement of neoliberal policies has been shown to predict other orientations and belief systems that legitimize group and system inequalities (Azevedo et al., 2019). Hartwich and Becker (2021) examined the situational effect of neoliberal beliefs, finding that exposure to neoliberal messages that prioritize freedom over justice and equality, individual success over public spirit, and distributions according to ability over need, induced anti-elite sentiment and that this was mediated by feelings of threat, unfairness, and hopelessness.

While the research described above is informative, from a cultural-psychological perspective the notion of ideology also includes laws, policies, institutions and practices embodying prescriptive and descriptive ideas about fair socioeconomic arrangements. Therefore, a sociocultural model of neoliberal ideology entails empirically investigating the dynamics of neoliberal belief systems (at an individual level) with neoliberal laws, institutions, and cultural practices and products as in the present analysis. To our knowledge, the empirical analysis presented in this paper is the first illustration within psychology and related fields of how neoliberal macro-structures influence distributive preferences and beliefs.

The question of the relationship between economic structures on the one hand and ideas, values, and culture on the other is longstanding. From Adam Smith to Karl Marx to contemporary sociologists and economists, whether and how market societies give rise to a certain ethos has been contentiously debated. Following Hirschman (1982), Fourcade and Healy (2007) typologize sociological and economic scholarship on the relationship between markets and values into three main streams: the first tradition belongs to classical theorists who viewed markets as a "civilizing" force enabling cooperation and creativity in otherwise selfish individuals (such as Adam Smith and Milton Friedman). The second tradition belongs to those who, according to Fourcade and 
Healy (2007), view markets as a "commodified nightmare," which largely includes Marxian work on alienation and exploitation under capitalist relations of production. What these two views have in common is that capitalism (or economic systems more broadly) is ultimately a powerful factor shaping morality and justice.

Contemporary models in economic sociology belong to a third tradition, what Fourcade and Healy (2007) describe as the "feeble markets" thesis, which provides a more nuanced narrative. In this view, the causal relationship between markets and moral values is not straightforward, and cultural and institutional legacies are important in shaping this relationship. In his classic work, The Protestant Ethic and the Spirit of Capitalism, Weber (1905/2013) famously argued that Protestantism—specifically, the Protestant work ethic—was especially amenable to the development and maintenance of capitalism in Western societies. Contemporary economists and economic sociologists argue for an even more complex picture, with some emphasizing the role of local context in modulating the relationship between markets and culture, and others for universal state interventions to foster market society despite cultural differences.

Fourcade and Healy (2007), for their part, advocate a view of markets as "moralized projects" that enable the "making" of moral persons. On this view, wage differences in market economies do not merely reflect payments and incentives for technological division of labor, but also signify individual status, merit, and worth according to the cultural narrative of capitalism. Zaki and colleagues (2021) coined market cognition to refer to a set of judgments and behaviors that are activated in the context of market societies. They argue that while markets can encourage prosociality in exchange relationships, they also promote the notion of humans as mainly motivated by selfinterest. As mentioned earlier, some scholars have referred to this "ultraindividualist" selfway as the entrepreneurial self or homo economicus, which personifies the ideas of Protestant work ethic and having the freedom to flourish (or perish) according to one's merits (G. Adams et al., 2019; Bhatia \& Priya, 2018).

The shift toward entrepreneurial identities, shaped by global neoliberal market forces, cuts across cultures. For instance, in an ethnographic study in Barbados, Freeman (2015) demonstrates that economic policy alterations aligned with neoliberalism have transformed cultural values and 
individual identities, especially among the middle class, to align more closely with the global economic status quo. She emphasizes the notion of "the self entrepreneurial project inextricable from enterprise and market sphere" (Freeman, 2015, p.3). Ethnographic research has also shown that neoliberal ideology shapes identity formation among Indian youth—shifting the emphasis toward productivity, competition, and personal achievement (Bhatia, 2017; Bhatia \& Priya, 2018). Our empirical investigation also bolsters the argument that dominant economic ideologies shape psychological outcomes, such as distributive justice beliefs across cultures. This further illuminates the notion that equity-based distributive justice beliefs are not necessarily innate or universal. Rather, the pervasiveness of equity beliefs could be explained by the dominance of macro-level economic structures that promote market-congruent values, beliefs, and attitudes (Ratner, 2019).

Despite the evidence illustrating a shift toward equity-based evaluations shaped by global neoliberal economic paradigms, our review still captures nuances in distributive justice beliefs across development, relationships, economies, and cultures. This suggests that, in line with contemporary approaches in sociology, the influence of global ideology and market systems on distributive justice beliefs is modulated by other cultural and psychological factors. Further, although we do not observe this empirically in our analysis, we believe that the relationship between socio-historical structures and human psychology is a reciprocal one, with the two levels of analysis reinforcing one another. In the present case, meritocracy as a descriptive belief and an equity-based distributive rule has been identified as the main contributor to the success of neoliberalism (Littler, 2017), especially in Protestant societies. In turn, neoliberalism undermines solidarity and redistribution by promoting competitive individualism and the narrative of meritocracy (Peck et al., 2018).

As psychological researchers, we should not disregard the manifestation of other justice principles present in counter-hegemonic social movements and collectives (Worth, 2018) despite the massive influence of neoliberalism. In line with decolonial approaches in psychology, one goal of this paper has been to critically examine the role of certain psychological literatures on propagating a rather ahistorical and arguably Eurocentric notion of equity-as-fairness, and to highlight research that counters such conceptualizations of justice. In investigating the political and economic circumstances for the development of neoliberalism, Dardot and Laval (2014) observe 
that this discourse has not only proliferated in the public sphere, but has also permeated domains of expertise, such as the government and the academy. Similarly, Adams and colleagues (2019) aim to elucidate the psychology of neoliberalism, while at the same time criticizing the neoliberalism of psychological sciences and advocating for its "decolonization." We suggest that future work pay attention to the other principles of justice—namely, need and equality — as they are manifested in anticolonial and local struggles against globalization, Western domination, and other forms of oppression-such as the Zapatistas in Chiapas or Kurds in Rojava. Further, psychological treatments of distributive justice should consider the influence of structural and ideological factors in shaping perceptions of fairness. We conclude by asserting that psychological sciences would benefit from the integrative approach of distributive beliefs - attending to macro- as well as micro-level factors.

\section{References}

Adams, G., Estrada-Villalta, S., Sullivan, D., \& Markus, H. R. (2019). The psychology of neoliberalism and the neoliberalism of psychology. Journal of Social Issues, 75(1), 189-216. http://dx.doi.org/10.1002/andp.19053221004

Adams, J. S. (1965). Inequity in social exchange. Advances in Experimental Social Psychology, 2, 267-299. https://doi.org/10.1016/S0065-2601(08)60108-2

Almås, I., Cappelen, A. W., Sørensen, E. Ø., \& Tungodden, B. (2010). Fairness and the development of inequality acceptance. Science, 328(5982), 1176-1178. https://doi.org/10.1126/science. 1187300

Asparouhov, T., Hamaker, E. L., \& Muthén, B. (2018). Dynamic structural equation models. Structural Equation Modeling: A Multidisciplinary Journal, 25(3), 359-388. https://doi.org/ 10.1080/10705511.2017.1406803

Azevedo, F., Jost, J. T., Rothmund, T., \& Sterling, J. (2019). Neoliberal ideology and the justification of inequality in capitalist societies: Why social and economic dimensions of ideology are intertwined. Journal of Social Issues, 75(1), 49-88. https://doi.org/10.1111/josi.12310 
Bay-Cheng, L. Y., Fitz, C. C., Alizaga, N. M., \& Zucker, A. N. (2015). Tracking homo oeconomicus: Development of the neoliberal beliefs inventory. Journal of Social and Political Psychology, 3(1), 71-88. https://doi.org/10.5964/jspp.v3i1.366

Beattie, P., Bettache, K., \& Chong, K. C. Y. (2019). Who is the neoliberal? Exploring neoliberal beliefs across East and West. Journal of Social Issues, 75(1), 20-48. https://doi.org/10.1111/ josi.12309

Becker, J. C., Hartwich, L., \& Haslam, S. A. (2021). Neoliberalism can reduce well-being by promoting a sense of social disconnection, competition, and loneliness. British Journal of Social Psychology, 60(3), 947-965. https://doi.org/10.1111/bjso.12438

Bettache, K., \& Chiu, C.-Y. (2019). The invisible hand is an ideology: Toward a social psychology of neoliberalism. Journal of Social Issues, 75(1), 8-19. https://doi.org/10.1111/josi.12308

Bhatia, S. (2017). Decolonizing psychology: Globalization, social justice, and indian youth identities. Oxford University Press.

Bhatia, S., \& Priya, K. R. (2018). Decolonizing culture: Euro-american psychology and the shaping of neoliberal selves in India. Theory \& Psychology, 28(5), 645-668. https://doi.org/https: //doi.org/10.1177/0959354318791315

Bland, A. R., Roiser, J. P., Mehta, M. A., Schei, T., Sahakian, B. J., Robbins, T. W., \& Elliott, R. (2017). Cooperative behavior in the ultimatum game and prisoner's dilemma depends on players' contributions. Frontiers in Psychology, 8, 1017. https://doi.org/https://doi.org/10. 3389/fpsyg.2017.01017

Blau, P. M. (2017). Exchange and power in social life. Routledge. https ://doi.org/10.4324/ 9780203792643

Boll, T., Ferring, D., \& Filipp, S.-H. (2003). Perceived parental differential treatment in middle adulthood: Curvilinear relations with individuals' experienced relationship quality to sibling and parents. Journal of Family Psychology, 17(4), 472. https://doi.org/10.1037/08933200.17 .4 .472

Bolton, G. E., \& Ockenfels, A. (2000). ERC: A theory of equity, reciprocity, and competition. American Economic Review, 90(1), 166-193. https://doi.org/10.1257/aer.90.1.166 
Bräuer, J., \& Hanus, D. (2012). Fairness in non-human primates? Social Justice Research, 25(3), 256-276. https://doi.org/10.1007/s11211-012-0159-6

Brooks, S. P., \& Gelman, A. (1998). General methods for monitoring convergence of iterative simulations. Journal of Computational and Graphical Statistics, 7(4), 434-455. https: //doi.org/https://doi.org/10.1080/10618600.1998.10474787

Brosnan, S. F. (2013). Justice-and fairness-related behaviors in nonhuman primates. Proceedings of the National Academy of Sciences, 110(Supplement 2), 10416-10423.

Brosnan, S. F., \& de Waal, F. B. (2003). Monkeys reject unequal pay. Nature, 425(6955), 297-299. https://doi.org/https://doi.org/10.1038/nature01963

Brosnan, S. F., \& de Waal, F. B. (2014). Evolution of responses to (un)fairness. Science, 346(6207). https://doi.org/https://doi.org/10.1073/pnas.1301194110

Brown, W. (2019). In the ruins of neoliberalism: The rise of antidemocratic politics in the West. Columbia University Press.

Camerer, C. F. (2003). Behavioral game theory: Experiments in strategic interaction. Russel Sage Foundation.

Cappelen, A. W., Hole, A. D., Sørensen, E. Ø., \& Tungodden, B. (2007). The pluralism of fairness ideals: An experimental approach. American Economic Review, 97(3), 818-827. https: //doi.org/10.1257/aer.97.3.818

Carson, A. S., \& Banuazizi, A. (2008).

That's not fair" similarities and differences in distributive justice reasoning between american and filipino children. Journal of Cross-Cultural Psychology, 39(4), 493-514. https://doi.org/ $10.1177 / 0022022108318134$

Cook, K. S., \& Hegtvedt, K. A. (1983). Distributive justice, equity, and equality. Annual Review of Sociology, 9(1), 217-241. https://doi.org/10.1146/annurev.so.09.080183.001245

Crouch, C. (2020). Post-democracy after the crises. John Wiley \& Sons.

Dahl, A. (2014). Definitions and developmental processes in research on infant morality. Human Development, 57(4), 241-249. https://doi.org/10.1159/000364919

Dardot, P., \& Laval, C. (2014). The new way of the world: On neoliberal society. Verso Books. 
Davey, L. M., Bobocel, D. R., Hing, L. S. S., \& Zanna, M. P. (1999). Preference for the Merit Principle Scale: An individual difference measure of distributive justice preferences. Social Justice Research, 12(3), 223-240. https://doi.org/10.1023/A:1022148418210

Davidai, S., \& Gilovich, T. (2018). How should we think about Americans' beliefs about economic mobility? Judgment \& Decision Making, 13(3).

Debove, S., Baumard, N., \& André, J.-B. (2017). On the evolutionary origins of equity. PLOS ONE, 12(3), e0173636. https://doi.org/10.1371/journal.pone.0173636

DePhillips, R. (2015). Quantifying neoliberalism: Shared variation and partial independence among several dimensions. Comparative Sociology, 14(6), 821-846.

Deutsch, M. (1975). Equity, equality, and need: What determines which value will be used as the basis of distributive justice? Journal of Social Issues. https://doi.org/10.1111/j.15404560.1975.tb01000.x

Donni, P. L., \& Marino, M. (2020). The role of collective action for the emergence and consolidation of democracy. Journal of Institutional Economics, 16(6), 831-862.

Elenbaas, L. (2019). Against unfairness: Young children's judgments about merit, equity, and equality. Journal of Experimental Child Psychology, 186, 73-82. https://doi.org/10.1016/j. jecp.2019.05.009

Essler, S., Lepach, A. C., Petermann, F., \& Paulus, M. (2020). Equality, equity, or inequality duplication? How preschoolers distribute necessary and luxury resources between rich and poor others. Social Development, 29(1), 110-125. https://doi.org/10.1111/sode.12390

Fehr, E., Bernhard, H., \& Rockenbach, B. (2008). Egalitarianism in young children. Nature, 454(7208), 1079-1083. https://doi.org/10.1038/nature07155

Fehr, E., \& Schmidt, K. M. (1999). A theory of fairness, competition, and cooperation. The Quarterly Journal of Economics, 114(3), 817-868. https://www.jstor.org/stable/2586885

Fiske, A. P. (1992). The four elementary forms of sociality: Framework for a unified theory of social relations. Psychological review, 99(4), 689-723. https://doi.org/10.1037/0033$295 \times .99 .4 .689$ 
Fiske, A. P. (1991). Structures of social life: The four elementary forms of human relations: Communal sharing, authority ranking, equality matching, market pricing. Free Press.

Fourcade, M., \& Healy, K. (2007). Moral views of market society. Annuual Revew of Sociology, 33, 285-311. https://doi.org/10.1146/annurev.soc.33.040406.131642

Franco-Watkins, A. M., Edwards, B. D., \& Acuff Jr, R. E. (2013). Effort and fairness in bargaining games. Journal of Behavioral Decision Making, 26(1), 79-90. https://doi.org/10.1002/bdm. 762

Frankena, W. K. (1966). Some beliefs about justice. University of Kansas, Department of Philosophy. Freeman, C. (2015). Entrepreneurial selves. Duke University Press.

Goudarzi, S., Pliskin, R., Jost, J. T., \& Knowles, E. D. (2020). Economic system justification predicts muted emotional responses to inequality. Nature Communications, 11(1), 1-9. https://doi.org/10.1038/s41467-019-14193-z

Graham, J., Haidt, J., Koleva, S., Motyl, M., Iyer, R., Wojcik, S. P., \& Ditto, P. H. (2013). Moral Foundations Theory: The pragmatic validity of moral pluralism. Advances in experimental social psychology (pp. 55-130). Elsevier.

Grzanka, P. R., Miles, J. R., Spengler, E. S., Arnett, J. E., \& Pruett, J. (2020). Measuring neoliberalism: Development and initial validation of a scale of anti-neoliberal attitudes. Social Justice Research, 33(1), 44-80. https://doi.org/10.1007/s11211-019-00339-3

Harvey, D. (2007). A brief history of neoliberalism. Oxford University Press.

Hatfield, E., \& Walster, G. W. (1975). Equity and social justice. Journal of Social Issues, 31(3), 21-43. https://doi.org/10.1111/j.1540-4560.1975.tb00001.x

Hatfield, E., Walster, G. W., \& Berscheid, E. (1978). Equity: Theory and research. Allyn \& Bacon. Henrich, J., Boyd, R., Bowles, S., Camerer, C., Fehr, E., Gintis, H., McElreath, R., Alvard, M., Barr, A., Ensminger, J., et al. (2005). "Economic man" in cross-cultural perspective: Behavioral experiments in 15 small-scale societies. Behavioral and brain sciences, 28(6), 795-815. https://doi.org/10.1017/S0140525X05000142

Hirschman, A. O. (1982). Rival interpretations of market society: Civilizing, destructive, or feeble? Journal of Economic Literature, 20(4), 1463-1484. https://www.jstor.org/stable/2724829 
Hochschild, J. L. (1981). What's fair?: American beliefs about distributive justice. Harvard University Press.

Homans, G. C. (1974). Social behavior: Its elementary forms. Harcourt.

Hui, C. H., Triandis, H. C., \& Yee, C. (1991). Cultural differences in reward allocation: Is collectivism the explanation? British Journal of Social Psychology, 30(2), 145-157. https: //doi.org/10.1111/j.2044-8309.1991.tb00931.x

Huppert, E., Cowell, J. M., Cheng, Y., Contreras-Ibáñez, C., Gomez-Sicard, N., Gonzalez-Gadea, M. L., Huepe, D., Ibanez, A., Lee, K., Mahasneh, R., et al. (2019). The development of children's preferences for equality and equity across 13 individualistic and collectivist cultures. Developmental science, 22(2), e12729. https://doi.org/10.1111/desc.12729

Inglehart, R., Haerpfer, C., Moreno, A., Welzel, C., Kizilova, K., Diez-Medrano, J., \& Puranen, B. (2014). World values survey: All rounds-country-pooled data file version.

Jost, J. T., Federico, C. M., \& Napier, J. L. (2009). Political ideology: Its structure, functions, and elective affinities. Annual Review of Psychology, 60, 307-337. https://doi.org/10.1146/ annurev.psych.60.110707.163600

Jost, J. T., \& Hunyady, O. (2003). The psychology of system justification and the palliative function of ideology. European Review of Social Psychology, 13(1), 111-153. https://doi.org/10. 1080/10463280240000046

Jost, J. T., \& Kay, A. C. (2010). Social justice: History, theory, and research. In S. T. Fiske, D. T. Gilbert, \& G. Lindzey (Eds.), Handbook of social psychology (pp. 1122-1165). John Wiley \& Sons.

Jost, J. T., \& Thompson, E. P. (2000). Group-based dominance and opposition to equality as independent predictors of self-esteem, ethnocentrism, and social policy attitudes among african americans and european americans. Journal of Experimental Social Psychology, 36(3), 209-232. https://doi.org/10.1006/jesp.1999.1403

Kienbaum, J., \& Wilkening, F. (2009). Children's and adolescents' intuitive judgements about distributive justice: Integrating need, effort, and luck. European Journal of Developmental Psychology, 6(4), 481-498. https://doi.org/10.1080/17405620701497299 
Kitayama, S. E., \& Cohen, D. E. (2007). Handbook of cultural psychology. The Guilford Press.

Kluegel, J. R., \& Smith, E. R. (2017). Beliefs about inequality: Americans'views of what is and what ought to be. Routledge.

Konow, J., Saijo, T., \& Akai, K. (2020). Equity versus equality: Spectators, stakeholders and groups. Journal of Economic Psychology, 77(102171). https://doi.org/10.1016/j.joep.2019.05.001

Lerner, M. J. (1974). The justice motive:"Equity" and "parity" among children. Journal of Personality and Social Psychology, 29(4), 539-550. https://doi.org/10.1037/h0036206

Lerner, M. J. (1977). The justice motive: Some hypotheses as to its origins and forms. Journal of Personality, 45(1), 1-52. https://doi.org/10.1111/j.1467-6494.1977.tb00591.x

Leung, K., \& Bond, M. H. (1984). The impact of cultural collectivism on reward allocation. Journal of Personality and Social Psychology, 47(4), 793-804. https://doi.org/10.1037/00223514.47.4.793

Leventhal, G. S., \& Anderson, D. (1970). Self-interest and the maintenance of equity. Journal of Personality and Social Psychology, 15(1), 57-62. https://doi.org/10.1037/h0029173

Liénard, P., Chevallier, C., Mascaro, O., Kiura, P., \& Baumard, N. (2013). Early understanding of merit in Turkana children. Journal of Cognition and Culture, 13(1-2), 57-66. https: //doi.org/10.1163/15685373-12342084

Littler, J. (2017). Against meritocracy: Culture, power and myths of mobility. Taylor \& Francis.

Madeira, A. F., Costa-Lopes, R., Dovidio, J. F., Freitas, G., \& Mascarenhas, M. F. (2019). Primes and consequences: A systematic review of meritocracy in intergroup relations. Frontiers in Psychology, 10:2007. https://doi.org/10.3389/fpsyg.2019.02007

Major, B., \& Kaiser, C. R. (2017). Ideology and the maintenance of group inequality. Group Processes \& Intergroup Relations, 20(5), 582-592. https://doi.org/10.1177/1368430217712051

Malti, T., Gummerum, M., Ongley, S., Chaparro, M., Nola, M., \& Bae, N. Y. (2016). "Who is worthy of my generosity?" recipient characteristics and the development of children's sharing. International Journal of Behavioral Development, 40(1), 31-40. https://doi.org/10. $1177 / 0165025414567007$

Marx, K. (1875/2008). Critique of the Gotha programme. Wildside Press. 
Massen, J. J., Van Den Berg, L. M., Spruijt, B. M., \& Sterck, E. H. (2012). Inequity aversion in relation to effort and relationship quality in long-tailed macaques (macaca fascicularis). American Journal of Primatology, 74(2), 145-156. https://doi.org/10.1002/ajp.21014

McCoy, S. K., \& Major, B. (2007). Priming meritocracy and the psychological justification of inequality. Journal of Experimental Social Psychology, 43(3), 341-351.

McNeish, D., \& Hamaker, E. L. (2020). A primer on two-level dynamic structural equation models for intensive longitudinal data in mplus. Psychological Methods, 25(5), 610-635. https: //doi.org/10.1037/met0000250

Meindl, P., Iyer, R., \& Graham, J. (2019). Distributive justice beliefs are guided by whether people think the ultimate goal of society is well-being or power. Basic and Applied Social Psychology, 41(6), 359-385. https://doi.org/10.1080/01973533.2019.1663524

Miller, D. (2001). Principles of social justice. Harvard University Press.

Muehlbacher, S., \& Kirchler, E. (2009). Origin of endowments in public good games: The impact of effort on contributions. Journal of Neuroscience, Psychology, and Economics, 2(1), 59-67. https://doi.org/10.1037/a0015458

Muthén, L. K., \& Muthén, B. (2017). Mplus user's guide: Statistical analysis with latent variables, user's guide. Muthén \& Muthén.

Napier, J. L., Bettinsoli, M. L., \& Suppes, A. (2020). The palliative function of system-justifying ideologies. Current Opinion in Behavioral Sciences, 34, 129-134. https://doi.org/10.1016/j. cobeha.2020.03.002

Nisbett, R. (2004). The geography of thought: How Asians and Westerners think differently... and why. Simon; Schuster.

Noh, J. Y. (2020). Children's developing understanding of merit in a distributive justice context. Journal of Child and Family Studies, 29(5), 1484-1492. https://doi.org/10.1007/s10826019-01606-2

Nozick, R. (2007). Anarchy, state, and utopia. Basic Books.

Peck, J., Brenner, N., \& Theodore, N. (2018). Actually existing neoliberalism. The Sage handbook of neoliberalism, 1, 3-15. http://dx.doi.org/10.4135/9781526416001.n2 
Proctor, D., Williamson, R. A., de Waal, F. B., \& Brosnan, S. F. (2013). Chimpanzees play the ultimatum game. Proceedings of the National Academy of Sciences, 110(6), 2070-2075. https://doi.org/10.1073/pnas.1220806110

Rabin, M. (1993). Incorporating fairness into game theory and economics. The American Economic Review, 1281-1302. https://www.jstor.org/stable/2117561

Rasinski, K. A. (1987). What's fair is fair-or is it? Value differences underlying public views about social justice. Journal of Personality and Social Psychology, 53(1), 201-2011. https: //doi.org/10.1037//0022-3514.53.1.201

Ratner, C. (2019). Neoliberal psychology. Springer.

Rawls, J. (2020). A theory of justice. Harvard University Press.

Rizzo, M. T., Elenbaas, L., Cooley, S., \& Killen, M. (2016). Children's recognition of fairness and others' welfare in a resource allocation task: Age related changes. Developmental Psychology, 52(8), 1307.

Rizzo, M. T., \& Killen, M. (2016). Children's understanding of equity in the context of inequality. British Journal of Developmental Psychology, 34(4), 569-581. https://doi.org/10.1111/bjdp. 12150

Saad Filho, A., \& Johnston, D. (2004). Neoliberalism: A critical reader. Pluto Press.

Sampson, E. E. (1975). On justice as equality. Journal of Social Issues, 31(3), 45-64. https : //doi.org/10.1111/j.1540-4560.1975.tb00996.x

Sampson, E. E. (1983). Equity and equality as sociohistorical principles of justice. Justice and the critique of pure psychology (pp. 35-41). Springer. https://doi.org/10.1007/978-1-46848163-1_4

Sandel, M. J. (2020). The tyranny of merit: What's become of the common good? Penguin Books.

Santos, H. C., Varnum, M. E., \& Grossmann, I. (2017). Global increases in individualism. Psychological Science, 28(9), 1228-1239. https://doi.org/10.1177/0956797617700622

Schäfer, M., Haun, D. B., \& Tomasello, M. (2015). Fair is not fair everywhere. Psychological Science, 26(8), 1252-1260. https://doi.org/10.1177/0956797615586188 
Schmidt, M. F., Svetlova, M., Johe, J., \& Tomasello, M. (2016). Children's developing understanding of legitimate reasons for allocating resources unequally. Cognitive Development, 37, 42-52. https://doi.org/10.1016/j.cogdev.2015.11.001

Schwartz, S. H. (1990). Individualism-collectivism: Critique and proposed refinements. Journal of cross-cultural psychology, 21(2), 139-157.

Shariff, A. F., Wiwad, D., \& Aknin, L. B. (2016). Income mobility breeds tolerance for income inequality: Cross-national and experimental evidence. Perspectives on Psychological Science, 11(3), 373-380. https://doi.org/10.1177/1745691616635596

Sigelman, C. K., \& Waitzman, K. A. (1991). The development of distributive justice orientations: Contextual influences on children's resource allocations. Child Development, 62(6), 13671378. https://www.jstor.org/stable/1130812

Singelis, T. M., Triandis, H. C., Bhawuk, D. P., \& Gelfand, M. J. (1995). Horizontal and vertical dimensions of individualism and collectivism: A theoretical and measurement refinement. Cross-cultural research, 29(3), 240-275.

Sloane, S., Baillargeon, R., \& Premack, D. (2012). Do infants have a sense of fairness? Psychological Science, 23(2), 196-204. https://doi.org/10.1177/0956797611422072

Smith, C. E., \& Warneken, F. (2016). Children's reasoning about distributive and retributive justice across development. Developmental Psychology, 52(4), 613-28. https://doi.org/10.1037/ a0040069

Starmans, C., Sheskin, M., \& Bloom, P. (2017). Why people prefer unequal societies. Nature Human Behaviour, 1(4), 1-7. https://doi.org/10.1038/s41562-017-0082

Surian, L., \& Franchin, L. (2017). Infants reason about deserving agents: A test with distributive actions. Cognitive Development, 44, 49-56. https://doi.org/10.1016/j.cogdev.2017.08.009

Tooby, J., \& Cosmides, L. (2005). Conceptual foundations of evolutionary psychology. John Wiley \& Sons, Inc.

Trump, K.-S. (2020). When and why is economic inequality seen as fair. Current Opinion in Behavioral Sciences, 34, 46-51. https://doi.org/10.1016/j.cobeha.2019.12.001 
Ulber, J., Hamann, K., \& Tomasello, M. (2015). How 18-and 24-month-old peers divide resources among themselves. Journal of Experimental Child Psychology, 140, 228-244. https://doi. org/10.1016/j.jecp.2015.07.009

Van den Bos, K., Peters, S. L., Bobocel, D. R., \& Ybema, J. F. (2006). On preferences and doing the right thing: Satisfaction with advantageous inequity when cognitive processing is limited. Journal of Experimental Social Psychology, 42(3), 273-289. https://doi.org/10.1016/j.jesp. 2005.04 .003

Voelkle, M. C., Gische, C., Driver, C. C., \& Lindenberger, U. (2018). The role of time in the quest for understanding psychological mechanisms. Multivariate Behavioral Research, 53(6), 782-805. https://doi.org/10.1080/00273171.2018.1496813

Weber, M. (1905/2013). The protestant ethic and the spirit of capitalism. Routledge.

Zaki, J., Neumann, E., \& Baltiansky, D. (2021). Market cognition: How exchange norms alter social experience. Current Directions in Psychological Science, 30(3), 231-241. https: //doi.org/10.1177/0963721421995492

Zhang, Z. (2020). The impact of social relationships on children's distributive justice. Developmental Psychology, 56(1), 103-116. https://doi.org/10.1037/dev0000855 